Article

\title{
The Impact of Organizational Culture on Customer Service Effectiveness from a Sustainability Perspective
}

\author{
Daniel Metz ${ }^{1,2, * \mathbb{C}}$, Liviu Ilieș ${ }^{1}$ and Răzvan Liviu Nistor ${ }^{1}$ \\ 1 Faculty of Economics and Business Administration, Babes-Bolyai University, 400591 Cluj-Napoca, Romania; \\ liviu.ilies@econ.ubbcluj.ro (L.I.); razvan.nistor@econ.ubbcluj.ro (R.L.N.) \\ 2 NTT DATA Romania, 400158 Cluj-Napoca, Romania \\ * Correspondence: daniel.metz@econ.ubbcluj.ro
}

Received: 23 June 2020; Accepted: 28 July 2020; Published: 3 August 2020

check for updates

\begin{abstract}
The conducted study focused on a multinational ITC (Information Technology and Communications) company. Empirical research aimed to evaluate organizational culture based on Denison's model through four features: capacity development, basic values, customer orientation, and goals and objectives. At the same time, the study analyzed service provided to customers, taking into account its three phases: pre-transaction, transaction, and post-transaction. As research methods, we used a questionnaire-based survey and direct observation. The results of the study demonstrate that the company has a strong culture based on an adequate core value system (shared by company members), innovative and effective human capital management practices, and customer orientation. All characteristics ensure the integration of sustainability principles into strategies, policies, and management practices of the company. At the same time, the authors develop a design and analysis model of the impact of organizational culture features on customer service effectiveness, highlighting that the four organizational culture features are good predictors for improving customer service effectiveness, which promotes an ethical business model and sustainable pursuit of economic, social and environmental performance. The study identified a set of good management practices and solutions in the design, operationalization, and monitoring of customer service.
\end{abstract}

Keywords: organizational culture; customer service effectiveness; sustainability; capability development; core values; customer focus; goals and objectives

\section{Introduction}

For most companies, customer service represents an important factor in retaining customers and in maintaining high profits, as well as in securing new customers. The issues related to customer service may negatively affect not only a company's image and the performance of frontline employees, but also the sales volume and customer retention. An increasing number of companies carry out surveys regarding customer needs and expectations in order to determine competitive customer service levels [1], (p. 63). The effectiveness of customer service is an important factor in ensuring a competitive advantage. A business company cannot grow and be competitive if it does not fully meet the needs and expectations of customers [2].

Improving the level of customer service from the perspective of sustainability is essential for a company's orientation towards ensuring customer satisfaction by customer loyalty, which costs much less than regaining lost customers or attracting new ones [1,3-6]. The improvement of customer service effectiveness can significantly enhance organizational effectiveness, as well as customer and employee satisfaction $[7,8]$. 
We cannot speak of effective service provided to customers without a strong organizational culture that integrates the principles of sustainability according to the "triple bottom line" concept, based on a firm and informed commitment from a company's leadership. A company's culture determines not only the employees' behavior and attitudes, but also supports the creation and strengthening of a customer service culture, helping to maintain and attract new customers. At the same time, respect for the customers and leadership setting an example are essential prerequisites in supporting the effort of managers and of other employees involved in the services provided to the customers, in order to maintain high standards [9].

This paper proposes a conceptual framework that examines the impact of organizational culture on customer service effectiveness at a multinational company in the IT industry from the perspective of integrating the principles of sustainability into the business model in order to help achieve current and strategic sustainability objectives in business.

The study of the literature indicates a deficiency—in terms of a solid methodology assessing the impact of organizational culture on customer service effectiveness-as a significant factor in securing customer satisfaction and loyalty from the perspective of sustainability. In this context, we believe that identifying key success factors to ensure the effectiveness of customer service as a measure of the organization's performance, as well as to effectively integrate sustainability objectives into the company's strategy and practices, allows managers to identify service malfunctions and develop appropriate measures to improve and monitor it. Emphasizing customer service effectiveness as a non-financial performance indicator, without disregarding the business' financial dimension, is adequate for the analyzed company, which has a strong orientation towards customers and innovation.

From the perspective of sustainability, the research focus on improving key management processes in the field of customer service, taking into account that the most important issue in achieving performance is not its measurement, but how key management processes are performed at the company level [10].

From an internal perspective, we believe that the business model developed in the paper made it possible to connect with the company's strategy, policies and management practices, and capitalizing on the positive customer experience database to improve customer service effectiveness. On the other hand, the study, from the client's perspective, allowed the ranking of the most important criteria/indicators for ensuring a high level of service to the client. In this context, regarding the principles of sustainability in the corporate culture, the study contains an analysis of the ways of effective integration in the company's strategy, policies, and practices.

Starting from the belief that business models in the current economic and social context must develop their potential to integrate sustainability into the business of the analyzed company [11,12], the business model developed in this paper aims not only to obtain better economic performance by increasing the efficiency of customer service, but also to improve the contribution to achieving ecological, environmental and social performance. There are studies on the characteristics of sustainable business models of corporations that argue that social and environmental concerns are included in the mission and objectives of corporations that aim to create positive social effects for stakeholders [13].

From a sustainability perspective, the business model that includes processes, procedures, practices and operational and strategic management systems, has the potential to provide a holistic perspective of the company's customer relationship processes, which allows it to reconfigure its business capacity to adapt as quickly and effectively as possible to a constantly changing business environment. As some authors argue, the integration of sustainability into business models requires a systemic vision that takes into account the global perspective and its various components, together with the interrelationships between them [14].

Despite all the important contributions of some recognized authors in the field, there is a lack of clarity, conceptual consensus and consistency in defining, promoting and applying business models for sustainability in some business areas [15-19]. At the same time, there is a lack of in-depth theoretical substantiation and applied studies in some specific areas of the business environment, including the IT 
industry. The low number of case studies and empirical analyses on sustainable business models and innovation in the field reflects the lack of theoretical substantiation $[11,14,20]$.

The inclusion of economic, environmental, and social aspects in a company's business model ensures the alignment of the interests of all stakeholder groups with a priority focus on customer expectations by creating superior value for them [17]. The company will need to transform these relationships by adopting a broader, long-term vision, enabling it to move to develop trust-based relationships with both key internal and external stakeholders $[18,21]$.

\section{Literature Review}

\subsection{Organizational Culture}

The interest in organizational culture is owed to the recognition of its role in ensuring company performance [22-31].

As organizational objectives become more specific over a longer term, organizations become increasingly formal and more institutionalized. The development of organizational values, beliefs and practices ensures the differentiation of the organization from others and it may determine its success. Ouchi [32] finds that interest in organizational culture has seen a considerable increase, considering that it is a key factor of organizational effectiveness.

Organizational culture is regarded as a difficult and complex concept by numerous researchers, having a common significance, which contains both explicit and implicit elements [26,33,34]. It can be approached as a collective and social system, built and shared by the members of the organization, which contains values, beliefs, rules, ideologies, myths and rituals that facilitate the employees' motivation and involvement in the performance improvement process, thus constituting a valuable source of effectiveness and efficiency within a company [33,34]. At the same time, it is considered a key element, whereby the strategic managers may influence and direct the organization's development and course of action, being aware that values and beliefs determine the mode in which people think, feel, behave, solve problems, decide, plan and organize their economic systems $[24,26,27,30,33,34]$.

Organizational culture is considered a critical factor in achieving success in business, including the implementation of sustainability based on an approach that promotes the achievement of social, environmental and economic objectives of companies [35].

More and more companies are concerned with developing a culture oriented towards sustainability, which ensures the integration of economic, social, and environmental policies in the vision, mission, values, and processes of the organization. The goal is to simultaneously improve social and human well-being while reducing environmental impact and ensuring the effective achievement of organizational goals [36]. In this context, companies have to face changes and transformations in corporate culture, and to respond not only to economic but also social and environmental challenges [37-39]. At the same time, the integration of sustainability principles into a company's strategy and practices involves a significant change in policies, products, and/or processes to minimize pollution and resource use, together with improving relationships with the community and stakeholders.

Organizational culture is conveyed throughout an organization and, at the same time, it is adjusted to certain internal and external contexts and to the organization's objectives, which requires continuous effort from a company's management in order to attain their objectives.

Managers who have a high level of expertise and adequate skills are capable of strengthening organizational culture by promoting fundamental values which they share with the other members of the organization. Cultural changes require continuous development of managers from all hierarchical levels in order to develop the potential of a company's employees. The major challenge that company managers face is supporting a culture based on competitiveness, subsequently enabling the promotion of an ethical and sustainable business model which facilitates changes when they are necessary [33,34]. 
For this purpose, we aimed to examine more carefully the concept of customer service and its relationship with organizational culture, for the development of an ethical and sustainable business model. The study also seeks to identify ways to consolidate and promote an organizational culture for sustainability, taking into account the company's concerns for the voluntary integration of social and environmental issues in the strategy and practices of the organization. Starting from the characteristics of the company, of the human resources, of the supplied products, and the clients, we must emphasize the fact that the management of the service provided to the clients has elements of uniqueness in terms of the different types of supplied products, clients and market segments. For this reason, starting from the similarities and differences in the implementation and operationalization of customer service, we aim to develop a model for its design and analysis.

To determine the impact of organizational culture on customer service, we sought to develop a model of organizational culture based on its dimensions/features, on the company's value system and on how the principles of corporate sustainability - with its three pillars: economic, social and environmental—influence organizational culture as a possible predictor of customer service.

The adoption of sustainability policies by the company facilitates the integration of corporate sustainability principles, not only by institutionalizing them throughout the organization through organizational culture but also in the form of specific objectives in the organization's strategies and practices.

Companies that adequately and effectively integrate the principles of sustainability must demonstrate a high level of orientation towards employees, customers, processes, the community, and the environment, which they must integrate into their strategy and business model $[40,41]$.

At the same time, companies that succeed in promoting long-term relationships based on cooperation and mutual trust with key stakeholders will be able to integrate social and environmental issues into their business strategy and model.

The values, convictions and principles underlying organizational culture make it a foundation for the management system and for the system of practices of an organization's management, also for the behaviors illustrating and strengthening such basic principles. The messages originating from an organization's culture are closely related to the organization's strategy and to the management practices, having a significant impact on the employees, behavior and performance [35,42]. A clear understanding of organizational culture is important to all leaders, as they influence the mode in which their organizations react to the business change requirements in relation to the dynamics of the external environment, respectively of the market. The attempt to change some values of the organization and of its members is only beneficial inasmuch as there is a change in the mode in which the company operates and the modalities in which the employees share its fundamental values.

Denison, in "Cultural Research Survey" [43], demonstrates that organizational culture is a strong instrument allowing key leaders, stakeholders and employees to understand the impact it has on organizational effectiveness as a performance indicator, thus learning how to redirect their culture in order to improve it [25-28,30,44,45].

Summarizing our review of the literature, we can say that the approach of organizational culture relies on theoretical perspectives, as well as on the increase in its survey area [45].

\subsection{Customer Service}

Customer service can be an excellent competitive weapon. It is more difficult to be imitated by competitors than other variables of the marketing mix, such as price or promotion. The company that can provide a high level of service provided to customers will find that it has a strong sales advantage in the market [46].

Customer service is currently regarded as a basic instrument in improving customer satisfaction and in securing a competitive advantage, taking into account the shifting of the emphasis from the creation of the brand to the creation of effective customer relations, by means of effective management and marketing services and by creating positive experiences with them [47]. At the same time, we can 
ascertain a change which focuses not only on the customer's behavior, but also on organizational strategies, aiming to improve the value provided to the customers, as well as their satisfaction $[7,48-50]$.

The meaning of the concept of "customer service" is different from one company to another; moreover, suppliers and their customers have a different perception of this concept. An increasing number of specialists regard customer service as an interface between management and marketing. In terms of sales, customer service can be considered a measure of the management's performance in relation to this interfacing activity between management and marketing, which also includes aftersales services. A competitive customer service retains customers, repeatedly fosters businesses, boosts customer purchases, creating a climate of trust, credibility and satisfaction. As a factor, improving customer satisfaction and loyalty can be associated with a successful marketing mix [7,51-56].

Lambert and Stock [57] view customer service as a significant component of a company's logistics, being 'materialized in management activities, methods, techniques and instruments ensuring the supply by the company of the products the customer wishes to procure' [57] (p. 118). If we take into account the benefits obtained by the customer together with the supply of the product, with the tangible features and intangible benefits (image, reputation) rendered by the product, we can say that customer service, as a component of management, adds value to the customer and, as a marketing component, ensures satisfaction and loyalty $[7,56]$.

In the fight for competitiveness, a company aims to achieve high customer service levels, using the fewest possible resources. Against this background, managers need to clearly define the customer service strategy, based on a rigorous scientific substantiation, without disregarding their customer experience. Without a scientifically substantiated customer service strategy and policy, having as support a customer base providing adequate information in real time, a company cannot attain a competitive advantage. The strategic approach of customer service, together with its positive customer experience, constitutes a means to successfully face strong competition ([58] (p. 226), [8] (p. 16)).

Only a strategic vision perceives customer service as essential for the end customer's experience and for the relation with the customers. Managers with a vision understand the true role of customer service and they manage to see the opportunities and the risks within the customer's experience. Customer service, 'when it is strategically approached, together with their positive experience, constitutes a means to successfully face the economic storm from an increasing number of markets' [8] (p. 15). Only an effective and performant customer service can become part of a company's culture, in which the employees have excellent performance, taking into account the fact that such performance is part of the organizational essence [59] (p. 2).

Customer service becomes an important weapon in the fight of ensuring competitiveness on the market in view of the diversification of products and the enhancement in customer requirements in an increasingly competitive market, which escalates difficulties in satisfying customer expectations and requirements. Companies with a strategic approach to customer service will reach adequate decisions in order to satisfy customer requirements and expectations in an effective manner, facilitating investments into employees and processes, as well as a prompt and effective answer to customers complaints by treating them in a wider context by which they can be differentiated on the market.

\section{Material and Methods}

The purpose of this study is to conduct research based on the perceptions of members of the analyzed company regarding customer service design and its operationalization in order to satisfy customer expectations and needs and provide adequate support to the decision-making system in the elaboration and monitoring of standards and of the measures for the improvement of this service's effectiveness. The general objective of this study consists of the development of a model for the assessment and analysis of the impact of organizational culture, represented by four traits (capacity development; core values; customer focus; goals and objectives), on customer service effectiveness within a multinational company from the ITC industry in Romania. This model is based on the 
Denison model, which highlights the interrelations between organizational culture and organizational performance, measured using the organizational effectiveness indicator.

The study's specific objectives refer to the assessment and analysis of the four traits of organizational culture within the analyzed company; the assessment and analysis of customer service and of its main components within the investigated company; the assessment of organizational culture, the determination and analysis of its impact, represented by the four traits, on customer service effectiveness; raising the awareness of the managers and of the other employees for a strategic approach to customer service (beyond service operationalization functions) to respond to customer questions and issues; ensuring appropriate support for the decision-making system in the process of not only strengthening the organizational culture but also developing monitoring standards and measures to improve customer service effectiveness to promote an ethical and sustainable business model.

The construct was based on relevant indicators, built on the basis of the questionnaire items, and was represented by primary variables, which allowed for an in-depth study of the potential statistical relations with direct application in analysis and decision-making. The employed indicators and the aggregated variables (obtained by adding up the primary variables) are: capacity development, represented by the variable $\mathrm{CD}$; core values, represented by the variable $\mathrm{CV}$; customer focus, represented by the variable $\mathrm{CF}$; goals and objectives, represented by the variable GO; effectiveness of customer service management practices, represented by the variable CSMG; pre-transaction effectiveness, represented by the variable PRTP; transaction effectiveness, represented by the variable TP; post-transaction effectiveness, represented by the variable PSTP; customer service effectiveness, represented by the aggregated variable CSE, made up by adding up the variables CSMG, PRTP, TP, PSTP.

The main working hypotheses are as follows:

Hypothesis 1 (H1). Between the variable capacity development (CD) and the variable customer service effectiveness (CSE) with its components (CSMG, PRTP, TP, PSTP), there is a significant and positive link.

Hypothesis 2 (H2). Between the variable core values $(\mathrm{CV})$ and the variable customer service effectiveness (CSE) with its components (CSMG, PRTP, TP, PSTP), there is a significant and positive link.

Hypothesis 3 (H3). Between the variable customer focus (CF) and the variable customer service effectiveness (CSE) with its components (CSMG, PRTP, TP, PSTP), there is a significant and positive link.

Hypothesis 4 (H4). Between the variable goals and objectives (GO) and the variable customer service effectiveness (CSE) with its components (CSMG, PRTP, TP, PSTP), there is a significant and positive link.

The research is exploratory and explanatory and is based on the questionnaire-based survey and direct observation, which allowed for a more in-depth analysis regarding the impact of organizational culture on customer service effectiveness. The basis from which the questionnaires were designed for the four features of organizational culture was Denison's model with all necessary adaptations imposed by the realities of the company in order to capture the specifics of the corporate culture of the analyzed company, as well as some aspects resulting from the Excellence Awards (MBNQA-Malcolm Baldrige National Quality Award and EFQM-European Foundation for Quality Management).

The empirical study is based on a homogenous sample made up of 215 members of the analyzed company, whose representativeness is provided by the fact that all employees (managers and employees without managerial functions) directly involved in the design, implementation, operationalization, and monitoring of customer service are included. After the collection and checking of the questionnaires, 186 valid questionnaires resulted with a response rate of $86.52 \%$. The statistical research conducted in order to identify the importance of the elements defining customer service from the viewpoint of customers for the segment selected of the research relies on a random sample made up of 28 customers. The random nature of the sample is secured by the systematic extraction procedure, which ensures the credibility of the information. 
The instrument employed for the opinion poll is the questionnaire, used for the registration of the data resulting from the statistical observation. The first questionnaire, as a source of data from the internal perspective (that of the processes), contains the corresponding items for assessing the traits of organizational culture considered in the study (Part A) and for assessing the defining elements of customer service (Part B). The second questionnaire, from the perspective of customers, measures the importance of the customer service elements, assigned by the customers upon making the purchases. The items for the assessment of the agreement, for both questionnaires, were measured on a Likert-type scale, with values ranging from 1 to 5 (1: total disagreement; 5 : total agreement). The simplicity of the questions and the codification of the answers facilitated the processing of the data and the statistical analysis of the results, without requiring complicated intermediate statistical analyses.

The obtained statistical data constitute the source for loading a database accessible for processing, using the STATA 16 software package for this purpose. The characterization of the statistical population, respectively of the research sample, was performed with the aid of the descriptive statistics indicators. The results of the statistical analysis of the association relations and the simple linear regression analysis facilitated the calculation of complex indicators that provide a valuable information base for strategic decision making to strengthen the organizational culture and improve customer service, effectively improving customer satisfaction and loyalty. At the same time, all the variables used in the study were the subject of reliability analysis which shows that all of them have good internal coherence (Cronbach's alpha coefficient $>0.8$ ). As a source of information, we mention the data provided by the questionnaires, the experience with the customer provided by the databases of the analyzed company, direct observation both regarding the company's employees and the human capital management practices used in the field, as well as effective contact with relevant clients.

\section{Results and Discussion}

Through the use of information technology, the analyzed company creates cutting-edge technology and offers solutions for sustainable development to their customers and to society, while contributing to solving social problems through their corporate activities that consider cultivating IT talent and the promotion of an ethical and sustainable business model.

In the business field, the company pursues innovation to provide social infrastructure and solutions specific to the business category based on advanced technologies, as well as maintaining a high level of customer service.

In social terms, within the group to which the analyzed company belongs, the CSR (corporate social responsibility) committee was established, elaborating the CSR charter of the group and outlining the specific priority issues among which the environmental protection occupies an important place. At the company level, all these aspects are included in the CSR manual that promotes IT education for the community, also securing and developing its own IT resources.

In the environmental field, answers to climate change are provided by reducing greenhouse gas emissions and promoting energy efficiency in data centers and office buildings, saving resources and energy, and green procurement as well as pollution prevention.

Notably, the CSR initiatives of the multinational group, respectively of the companies that the multinational group consists of, were appreciated and included in the following "Environmental, Social and Governance" (ESG) indices that promote sustainability: Dow Jones Sustainability World Index (DJS); FTSE4Good Index; FTSE Blossom Japan; Prime Rating by oekom; RobecoSAM Sustainability Award Gold Class.

The ESG criteria for sustainability are the basis of the company's evaluation, which is the subject of the study and the reason why the sustainable development objectives are incorporated in the management strategy of the group and the component companies in the medium term (2019-2021). 


\subsection{Organizational Culture Trait Analysis}

In this study, organizational culture is assessed based on the respondents' perception regarding the following four traits: employee capacity development; sharing of core values; customer focus; goals and objectives, represented by the variables $\mathrm{CD}, \mathrm{CV}, \mathrm{CF}$, and GO.

To capture the relevant aspects of the organizational culture and customer service, the perceptions of the survey respondents depended on the aggregation at the sample level. At the same time, it sought to focus on observable and measurable aspects of culture, such as human capital management practices, fundamental values of the company, and customer orientation, together with goals and objectives.

For the purpose of statistical analysis, reliability analysis was conducted in advance, and its synthetic results (Table 1) indicate that all four variables, in terms of their construction, have good internal coherence, stated by the Cronbach's alpha coefficient, which registers the following values for the variables: CD (0.8324); CV (0.8713); CF (0.9667); GO (0.8079).

Table 1. Reliability analysis test scale.

\begin{tabular}{ccccc}
\hline Variable & Sign & $\begin{array}{c}\text { Number of Items } \\
\text { in the Scale }\end{array}$ & $\begin{array}{c}\text { Average Interitem } \\
\text { Covariance }\end{array}$ & $\begin{array}{c}\text { Scale Reliability } \\
\text { Coefficient Alpha }\end{array}$ \\
\hline CD & + & 9 & 0.2254628 & 0.8324 \\
CV & + & 14 & 0.1775736 & 0.8713 \\
CF & + & 15 & 0.351012 & 0.9667 \\
GO & + & 8 & 0.1468286 & 0.8079 \\
\hline
\end{tabular}

Note: CD—capacity development; CV—core values; CF—customer focus; GO—goals and objectives.

Next, we will characterize these variables with the aid of the descriptive statistics indicators (mean, standard deviation, standard error, coefficient of variation), as presented in Table 2.

Table 2. Tabstat CD CV CF GO, statistics (count mean sd semean cv); number of observations = 186 .

\begin{tabular}{ccccc}
\hline Stats & CD & CV & CF & GO \\
\hline $\mathrm{N}$ & 186 & 186 & 186 & 186 \\
mean & 4.1174771 & 4.2310280 & 4.214953 & 4.184579 \\
sd & 0.5239403 & 0.4429169 & 0.3852967 & 0.4848366 \\
se(mean) & 0.0506512 & 0.0428184 & 0.0372480 & 0.0568709 \\
cv & 0.1307407 & 0.104683 & 0.0914119 & 0.1158627 \\
\hline
\end{tabular}

\subsubsection{Capacity Development}

Capacity development, represented by the variable $\mathrm{CD}$, expresses the fact that the analyzed company makes continuous investments in the development of employees' skills in order to remain competitive and to respond to the ongoing commercial needs, as well as the modalities in which it ensures the development of employees' skills and competences for the most effective involvement possible [30,31].

The aggregated variable $C D$, made up of 9 primary variables, has an average of 4.1174 and it has a standard deviation considered good in terms of variation of responses in relation to the mean (0.5239). The standard error (0.0506) indicates good contiguity between the variable's average and its true value in relation to the total statistical population. The low variation coefficient $(0.1307)$ means that the statistical population on which the calculation of this variable was based has good homogeneity rate (Table 2).

According to the respondents' perception, the primary variables which register the best scores refer to the following aspects: employee capacity development is regarded as an important source of competitive advantage (4.2813); the employees' specific job skills enable the solving of issues in the company (4.2182); permanent investments in the development of employees' skills to secure competitive advantage and to respond to customer needs (4.1967); the securing of the skills needed 
for the employees' specific tasks to facilitate problem solving at the workplace, achieved by means of adequate and effective training (4.1093).

The analysis and interpretation of results indicates that the development of employees' skills and competences, represented by the variable CD, ensures good employee involvement and cooperation, organized in teams, in view of fulfilling the company's objectives.

"Capacity development" analysis as a feature of organizational culture provides a vivid and systematic picture of employee capacity development through appropriate training programs, together with innovative and effective human capital management practices, and facilitates the integration of sustainability principles into the analyzed company culture.

\subsubsection{Core Values}

Core values, represented by the variable CV, refers to the fact that the members of the company share a system of values which creates a sense of identity, together with a clear set of expectations, and it expresses the modes in which its development and strengthening are ensured, as well as performance improvement at organizational level. The aggregated variable $C V$, made up of 14 primary variables (items), registers an average value of 4.2310 and it has a standard deviation considered good in terms of variation of responses in relation to the average (0.4429). The standard error $(0.0428)$ indicates good contiguity between the variable's average and its true value in relation to the total statistical population, and the low variation coefficient $(0.1046)$ means that the statistical population on which the calculation of this variable was based has good homogeneity rate (Table 2).

According to the respondents' perception of the mode in which the company's leadership promotes a system of values based on high standards, shared with the other members, the primary variables registering the highest appreciations (scores) refer to the following aspects: the existence of a clear and coherent system of values in the company, that ensures the promotion of an ethical and sustainable business model (4.3092); the members of the company share a set of values that create a sense of identity and a clear set of expectations (4.2911); the actual involvement of the company's leadership for the elaboration and clear definition of an adequate system of values shared with the company's employees (4.2864); the managers prove responsibility for their actions and results and for successes and failures (4.2429); the company's managers show care for people (4.2588); the company's managers adopt a conduct based on the recognition of performance (4.2395); company culture is formed around its fundamental values, based on high standards (4.1401).

The following are also based on the perception of the respondents to the questionnaire regarding the first 10 basic values of the investigated company, ranked in the order of their average scores: clients first (4.78); innovation (4.75); team work (4.66); communication (4.62); care for people (4.59); leadership (4.52); integrity (4.48); the right to private life (4.37); responsibility (4.34); dedication (4.18).

These results confirm that the analyzed company has managed to strengthen a system of common values, shared by its members, thus ensuring the promotion of an ethical and sustainable business model.

The analysis of "core values" as features of organizational culture highlights the fact that the analyzed company managed to consolidate a system of fundamental values that are shared by its members, thus ensuring the integration of sustainability principles in the organization's culture.

\subsubsection{Customer Focus}

Customer focus expresses the mode in which the company's members understand and react with regard to the satisfaction of customer requirements and expectations, thus anticipating their future needs. At the same time, it indicates the extent to which the individual members of the company are prompted to deal with customer satisfaction and the fulfillment of customer requirements and expectations.

The variable CF, made up of 15 primary variables (items), registered an average of 4.2149 and it has a standard deviation considered good in terms of variation of responses in relation to the average 
(0.3852). The standard error (0.0372) indicates good contiguity of the variable's average to its true value in relation to the total statistical population. The variation coefficient is low (0.0914), which means that the statistical population, based on which this variable was calculated, has good homogeneity.

In the respondents' perception, the most appreciated aspects (items) related to customer focus with the related scores refer to the fact that:

- The company's leadership: takes into account customer recommendations and its experience with them (4.2910); is effectively concerned with the determination of customer requirements, expectations and preferences (4.2857); encourages direct contact of frontline employees with customers (4.2614); determines the key factors which induce the effectiveness of customer relations (4.2382); maintains a permanent relation with customers to inform them accurately and in due time regarding the orders and any potential delays (4.2102).

- The values of the organization are connected to customer requirements and expectations (4.3288).

- The employees prove in-depth understanding of customer needs and desires (4.2007).

As indicated below, the company has a strong customer focus, which helps the managers to effectively and efficiently manage the organization in order to improve operational performance and the performance standards of customer service.

The analysis of the "customer focus" feature and the sustainability objectives contained in the company's CSR charter, and effectively integrated into management practices, shows that the company's leadership ensures the integration of sustainability principles in the company's strategies, policies, and practices, for constructing "the future society" together with its customers.

\subsubsection{Goals and Objectives}

Successful organizations also have a clear sense of purpose and of direction, which defines the organizational and strategic objectives, expressing a vision of what the organization will look like in the future $[25,27,31,60]$. If the organizational strategic goals and objectives are related to the mission, vision and strategy, they provide a clear course of action for the company and its members in their activity.

According to the data in Table 2, the variable GO, made up of 8 primary variables, registers an average of 4.1845 and it has a standard deviation considered good in terms of variation of responses in relation to the average $(0.4848)$. The standard error $(0.0568)$ indicates good contiguity of the variable's average to its true value in relation to the total statistical population. The variation coefficient is low (0.1158), which means that the statistical population, based on which this variable was calculated, has good homogeneity.

According to the perspective of customers, the primary variables (the items) with the highest scores which make up the GO variable refer to the following aspects: there is wide consensus within the company regarding the organizational objectives (4.2782); there is a clear set of objectives, based on vision, mission, and strategy, which provides each member of the company with a clear direction in their activity (4.2087); the company's leaders establish and communicate the objectives in a clear manner, at all organizational levels (4.1687); the company's leaders determine clear, realistic and challenging objectives (4.1977); the company's strategic goals and objectives, defined clearly, are based on high, well-substantiated standards (4.1016), and they create a joint feeling of commitment and responsibility for the company's members (4.1772).

We also found that the company has a clear sense of purpose and definition of the organizational objectives, thus ensuring the promotion of an ethical and sustainable business model. At the same time, the company's management monitors the progress recorded in relation to the fulfillment of the declared objectives in an effective manner.

As it results from the analysis of the "goals and objectives" feature, the analyzed company, through the sustainability objectives, ensures the integration of the economic, social and environmental aspects in the mission, vision, values, and processes of the organization. 
Following the analysis of the four variables, we can see that the company has a strong organizational culture based on the commitment of leadership that emphasizes common core values, customer orientation, innovation, and human capital practices, that promotes without neglecting employees, thus facilitating the integration of sustainability principles and objectives into company strategies, together with policies through effective collaboration with stakeholders, confirmed by the organizational model of sustainability proposed by Hollingworth [52] and other authors [35,53].

\subsection{Customer Service}

The diversity of IT companies, categorized by organizational features, the provided products and the quality of the employees (to which the customer features are added and in our case are of "business-to-business" type), make customer service impossible to be generalized for all the market segments in which the company acts, even if its analysis indicates common practices or certain similarities.

To identify the most important elements which ensure a competitive customer service, a representative market segment was selected for the products of the analyzed company that secure a significant share of the sales. The emphasis was placed on the assessment of the services provided to the company's main customers, respectively on their requirements and expectations.

We shall approach customer service from an internal perspective (that of processes specificity), which measures the efficacy of the processes whereby the organization creates value by implementing competitive effective organizational processes, without disregarding the perspective of customers, which, in turn, measures the effectiveness of the service by how the customers experience the relation with the supplier [61]. Murphy and Knemeyer define customer service through the ability of management to satisfy customers in terms of trust, communication and ease of doing business (convenience) [46] (p. 137). Other authors focus on defining customer service in terms of product availability, ease of ordering, speed of delivery, and after-sales support [54].

Against this background, starting from the specific nature of the products, activities and processes, and taking into account the features of the analyzed company, it was considered appropriate to use the LaLonde and Zinszer model [62], based on a major study of customer service practices, to assess and analyze customer service. The authors suggested that customer service can be examined in three stages, with the following composition: pre-transaction: customer service policy, commitment to the customers, organizational structure, accessibility, system flexibility; transaction: the consistency of the order cycle, information on the order status, system accuracy, order response rate, etc.; post-transaction: monitoring and warranty at the level desired by the customer, availability of technical assistance post-warranty, management of complaints, etc. [7,54,55,57,63-68].

\subsubsection{The Customer Service Effectiveness Variable}

The use of non-financial indicators for customer service effectiveness, represented by the variable CSE with its components, is adequate for the research as it ensures a good relationship with the company's strategies and policies, based on the vision, mission, and key success factors $[8,69,70]$, which allows measurement of customer service performance based on the information regarding the satisfaction of their requirements and expectations. This is facilitated by the company's strong focus on innovation, by providing customers with services that leverage digital and other advanced technologies. At the same time, it allows the company to identify the strategies which offer the highest potential to attain the objectives of customer service and supports the alignment of management processes, decision-making and the measurement of performance with the achievement of strategic objectives, thus contributing to the awareness of the managers and of the other employees regarding the importance of customer service as a key success factor in ensuring competitive advantage $[7,8,46,54,57,63,71,72]$.

If the construct of variables that express the features of organizational culture is based on Denison's model, the variables identified and analyzed in customer service research, strategically approached, are represented by related management practices and organizational behaviors integrated into the 
company's business strategy and associated with customer service effectiveness as a non-financial indicator of performance, both from an internal perspective and from a customer perspective.

The construct and the analysis of the CSE variable from an internal perspective are based on a customer service audit. Thus, the internal audit conducted from an internal perspective, based on the perception of the respondents to the questionnaire, allowed for the measurement and analysis of the specific objectives, respectively of the standards and of the customer service level attained by the company; the relation between its key departments, to ensure a competitive service; the provision of corporate information for the development and update of the customer database and of the opportunities and methods for its improvement. As an effective instrument for the analysis of these variables and of the components which make it up, the internal audit facilitated the highlighting of management factors and practices that have an effective contribution to the competitiveness of customer service within the company, as well as awareness among the company members regarding its importance and customer experience, with positive effects observed on the improvement of service effectiveness, an important source of customer satisfaction [57] (p. 133). All this means that the effectiveness of customer service is closely linked to the company's ability to satisfy the customer.

For the analysis of customer service and its components, represented by the variables: CSMG, PRTP, TP, PSTP and CSE; we shall resort to the reliability analysis (Table 3), which indicates that all five variables have very good internal coherence, highlighted by Cronbach's alpha coefficient, whose values range between 0.9164 and 0.9647 (Table 3).

Table 3. Reliability analysis test scale.

\begin{tabular}{ccccc}
\hline Variable & Sign & $\begin{array}{c}\text { Number of Items } \\
\text { in the Scale }\end{array}$ & $\begin{array}{c}\text { Average Interitem } \\
\text { Covariance }\end{array}$ & $\begin{array}{c}\text { Scale Reliability } \\
\text { Coefficient Alpha }\end{array}$ \\
\hline CSMG & + & 18 & 0.3720405 & 0.9362 \\
PRTP & + & 16 & 0.2542458 & 0.9373 \\
TP & + & 11 & 0.2484527 & 0.9647 \\
PSTP & + & 13 & 0.2813421 & 0.9164 \\
CSE & + & 4 & 0.2104685 & 0.9624 \\
\hline
\end{tabular}

Note: CSMG—effectiveness of customer service management practices; PRTP—pre-transaction effectiveness; $\mathrm{TP}$ — transaction effectiveness; PSTP—-post-transaction effectiveness; CSE—customer service effectiveness.

Next, we will move on to the characterization of these variables with the aid of the descriptive statistics indicators (mean, standard deviation, standard error, coefficient of variation).

Regarding customer service, according to the data in Table 4, the indicators of the descriptive statistics point out the fact that all variables regarding customer service register relevant values for the employed statistical model: as a standard deviation, values range between 0.4008 and 0.6779 ; as a standard error, values range between 0.0863 and 0.0961 ; as a coefficient of variation, values range between 0.0911 and 0.1172 , which confirms the validity of the construct. In the order of the average scores registered, the best values are registered by the variable PRTP, closely followed by the variables CSE, TP, PSTP, CSMG.

Table 4. Tabstat CSMG PRTP TP PSTP CSE. Statistics (count mean sd semean cv); number of observation $=186$.

\begin{tabular}{cccccc}
\hline Stats & CSMG & PRTP & TP & PSTP & CSE \\
\hline $\mathrm{N}$ & 186 & 186 & 186 & 186 & 186 \\
mean & 4.171405 & 4.295238 & 4.215517 & 4.196429 & 4.219647 \\
sd & 0.6779183 & 0.495192 & 0.4942714 & 0.4008919 & 0.4310058 \\
se(mean) & 0.0940104 & 0.0863524 & 0.0917839 & 0.0883571 & 0.0961376 \\
cV & 0.1025156 & 0.0911885 & 0.1172505 & 0.0955317 & 0.1013042 \\
\hline
\end{tabular}




\subsubsection{The Effectiveness of Management Practices Variable}

The effectiveness of management practices, represented by the variable CSMG, as a component of the variable CSE, contains 18 primary variables (items) and it registers an average of 4.1714 (Table 4). It highlights the company's factors and practices that determine the effectiveness of customer service and express the modalities whereby the company provides significant support to customer service design and operationalization.

An analysis of the primary variables which make up the CSMG variable based on the respondents' perceptions regarding the questionnaire, highlights the existence of strong support of management practices to ensure customer service effectiveness. We emphasize in this regard the fact that the management of the analyzed company has coherent and adequate customer service strategies (4.16); ensures a strong commitment to the top management regarding customer service strengthening (4.17); ensures effective cooperation between the key departments involved in the relationship with the customers (4.13); focuses on innovation (4.28); organizes training for employees to provide working instruments (guidelines, operational procedures, working instructions etc.) in order to optimize the customer's internal activity (4.08); effectively implements customer relationship management (4.28); through its employees, communicates efficiently with the customer regarding the exchange of information (4.27); through its analysis of customer profitability, facilitates the decisions regarding customer service design and operationalization (4.29); through the marketing efforts, in its relationship with the customer, focuses on customer retention (4.11) and on acquiring new customers (4.04); maintains a high quality of customer service by successfully applying the TQM (Total Quality Management) principles (4.18); sets up standards and monitors the technical performance of customer service (4.19); develops customer assistance standards, so as to constantly provide excellent customer services (4.25); ensures effective communication in the relationship with the customers (4.16).

All this information demonstrates that the analyzed company, using a coherent system of management practices, has the support needed to ensure customer service effectiveness by satisfying the current and future requirements and expectations of customers.

\subsubsection{The Pre-Transaction Variable}

Pre-transaction, as a component of customer service, represented by the variable PRTP, contains 16 primary variables (items) and it registers an average of 4.2952 (Table 4). It highlights the activities regarding the determination of customer service policies and objectives, customer information, adequate organization, flexibility of the system, and counseling, particularly in the case of customers with insufficient experience in the field.

Taking into account the respondents' perceptions regarding the primary variables that form the variable PRTP, it is found that the most relevant aspects which determine pre-transaction effectiveness refers to the fact that within the company, the priorities of customer service are established based on the clear and objective understanding of customer requirements (4.38); the employees have adequate abilities to satisfy the customer's orders in accordance with their requirements (4.34); a customer service policy exists, which is adequate and known by customers and employees (4.33); there are clear, specific and measurable objectives for customer service (4.29); the key components of customer service are identified, taking into account their expectations and requirements, as well as the features of the organization (4.29); statements regarding customer service are accompanied by specific objectives with reference to modalities in which objectives need to be attained (4.28); customer service standards, stated in specific terms, ensure the general success of sales (4.26); the key factors influencing the procurement decisions of customers are determined (4.23); advisory programs are elaborated for the less experienced customers (4.21). 


\subsubsection{The Transaction Variable}

Transaction, as a component of customer service, represented by the variable TP, contains 11 primary variables (items) and it registers an average of 4.2155. It indicates activities related to the determination of customer service policies and objectives, customer information, proper organization, flexibility of the system and counselling, particularly in the case of customers with insufficient experience.

Observing the respondents' perceptions regarding the primary variables that form the TP variable, we find that the most relevant aspects which determine the effectiveness of the transaction refer to the fact that the company's management ensures compliance with the technical specifications of the products which are the object of the offer (4.33); ensures that the time standards that are established to respond to customer requirements are strictly observed (4.27); ensures accurate information, in real time, regarding the orders and the potential issues with the customers (4.25); initiates effective response actions to the urgently requested orders (4.23); evinces firm commitment for compliance with the order supply schedule as established with the customers and for their information in real time on potential delays which may occur $(4,21)$; ensures that the incoming orders are monitored and reported on a daily basis in the processing system (4.19); ensures that the order cycle corresponds to customer expectations and requirements, based on compliance with the contractual clauses (4.17); ensures that the documents regarding the orders are simple, precise and highly accurate (4.17); ensures that there are clear rules and procedures of conduct, which ensure confidentiality (4.29).

\subsubsection{The Post-Transaction Variable}

Post-transaction, as a component of customer service, represented by the variable PSTP, contains 13 primary variables (items) and it registers an average of 4.1964 (Table 4). It expresses the activities regarding the provision of technical assistance and of the guarantee regarding the levels expected by the customers, the monitoring of product functionality, the treatment and solving of customer complaints, the solving of the issues requested by the client (in the warranty period, as well as in the post-warranty period) according to the contractual clauses, etc.

Starting from the respondents' perceptions regarding the primary variables that form the PSTP variable, we find that the most relevant aspects which determine post-transaction effectiveness refer to the fact that the company's management provides customer assistance/support, taking into account their skills and experience (4.37); provides advice and recommendations to ensure the effective functionality of the product in accordance with the technical specifications (4.25); notifies the delays in solving potential issues related to the functionality of the provided product (4.23); has a systematic and effective program based on feedback from the customers to assess and control customer service effectiveness (4.21); updates the database on an ongoing basis according to its experience with them in order to ensure consistent information regarding customer appreciations, issues and complaints (4.20); initiates prompt and effective actions for the settlement of customer complaints (4.19); ensures employee availability to solve issues requested by the customer regarding product functionality, such as the expansion of the area of requirements and the improvement of performance (4.19); provides a prompt response to customer requests for technical assistance (4.17); takes part in active partnerships with the customers (4.17). The analysis of the variables that represent customer service shows that the results of the internal audit are also supported by the conclusions of the external audit (based on the customer perspective) regarding the assessment of element importance that makes up customer service. For this purpose, a simple questionnaire addressing the customers was drawn up, which contained 18 criteria/indicators as defining elements of customer service provided by the company. The questionnaire was addressed to a sample of 28 customers who were considered relevant to the company's business in the researched market segment. They were requested to assess the importance of these criteria/indicators in their relationship with the company as a supplier. Following the processing of the questionnaires received from the customers, a list was made up, with a hierarchy of the criteria/indicators established and accepted by them. In the order of importance awarded by the customers, the first 10 criteria with the 
related average scores are the following: the capacity to provide advice and assistance in the stage of product implementation and operationalization with the customer (4.88); prompt response to customer requests for assistance (4.85); competent technical representatives (4.82); ensuring and maintaining confidentiality (4.73); quality (specific competencies) and honesty of the sales force (4.65); creating and developing prompt partnerships with the customer (4.60); the company's capacity to observe the term for the performance of order (4.47); effective communication in real-time (4.43); mode of treatment and response to complaints (4.28); the order cycle corresponds to customer expectations and requirements (4.26).

If the company does not measure or analyze these criteria/indicators, the recognition of customer service effectiveness, as a performance indicator, shall be as decided by the customer.

To establish the validity of the construct for the CSE variable and the relevance of the four variables that compose it (CSMG, PRTP, TP, PSTP), we proceeded to measure and analyze the statistical association/correlation relations between the CSE variable and the variables that compose it, using the correlational analysis results as presented in Table 5. From the data analysis, it turns out that the variable CSE registers significant, positive, and very strong correlations with all the variables that compose it (the correlation coefficients are between 0.9201 and 0.9412).

Table 5. Correlate CSE CSMG PRTP TP PSTP (obs. = 186).

\begin{tabular}{cccccc}
\hline Variable & CSE & CSMG & PRTP & TP & PSTP \\
\hline CSE & 1.0000 & - & - & - & - \\
CSMG & 0.9412 & 1.0000 & - & - & - \\
PRTP & 0.9201 & 0.8152 & 1.0000 & - & - \\
TP & 0.9396 & 0.8628 & 0.8242 & 1.0000 & - \\
PSTP & 0.9228 & 0.8444 & 0.7724 & 0.8157 & 1.0000 \\
\hline
\end{tabular}

At the same time, we can find that there are significant, strong and very strong correlations between all pairs of variables that form the CSE variable, taking into account the fact that the correlation coefficients are positive and range between 0.7724 and 0.9412 , which demonstrates that the construct of the CSE variable is accurate and relevant for the needs of our analysis.

The analysis of the variables that ensure customer service effectiveness in increasingly competitive markets with ever higher standards of competitiveness indicates that the company places importance on customer service, which it considers a key factor of success in securing the competitive advantage over the short and long term. Numerous studies confirm the fact that the consideration of competition requires that companies focus on ensuring competitive customer service levels, which, together with product quality, represent important sources for ensuring customer satisfaction and loyalty $([8,46,54,63,71-73]$, (p. 2)).

\subsection{The Impact of Organizational Culture on Customer Service Effectiveness}

Starting from the importance of customer service approached strategically and within a multinational company from the ITC area, we aimed to determine the impact of organizational culture through the four traits on the effectiveness of customer service with its components in order to develop a program for its improvement based on the theory and the best practices in the field [74,75]. Conrad and his collaborators [76] investigated and highlighted the existence of a relation between a company's cultural typology and the activities dedicated to customer service.

To determine the impact of the independent variables, $C D, C V, C F, G O$, on the dependent variables, CSMG, PRTP, TP, PSTP, CSE, we proceeded to conduct simple linear regression analysis. Before applying linear regression analysis, we conducted a check regarding the validity of fulfilling the conditions necessary for its application for all econometric models used in this study. Based on the evaluation model and analysis used, at the level of the company employees, the extent to which the variables that express the effectiveness of customer service change depending on the change in 
independent variables expressing the organizational culture was quantified. The information obtained is based on a valid statistical study concerning the most relevant statistical tests.

4.3.1. The Impact of the Independent Variable CD on the Dependent Variables CSMG, PRTP, TP, PSTP, CSE

Based on the results of the regression analysis (Table 6), we can find that, statistically, the independent variable $\mathrm{CD}$ has a significant and positive impact on the dependent variables which state the customer service level. This statement is supported by the " $F$ " test, where Prob $>F=$ 0.0000 . We can also find that there is a linear econometric model between the independent variable $\mathrm{CD}$ and the five dependent variables. The variation of the $\mathrm{CD}$ variable explains, to a rate of $47.02 \%$, the variation of the variable CSMG; the variation of the variable PRTP $(34.29 \%)$; the variation of the variable TP $(38.47 \%)$; the variation of the variable PSTP $(44.75 \%)$; the variation of the variable CSE $(46.17 \%)$.

Table 6. The impact of the independent variable CD on the dependent variables CSMG, PRTP, TP, PSTP, CSE.

\begin{tabular}{ccccccc}
\hline Dependent Variable & N & Prob $>$ F & R-Squared & Coef. & $\boldsymbol{t}$ & $\boldsymbol{p}>|\boldsymbol{t}|$ \\
\hline CSMG & 186 & 0.0000 & 0.4702 & 0.4697228 & 7.65 & 0.000 \\
PRTP & 186 & 0.0000 & 0.3429 & 0.4858687 & 6.43 & 0.000 \\
TP & 186 & 0.0000 & 0.3847 & 0.3698693 & 5.48 & 0.000 \\
PSTP & 186 & 0.0000 & 0.4475 & 0.4820633 & 6.56 & 0.000 \\
CSE & 186 & 0.0000 & 0.4617 & 0.4518810 & 7.01 & 0.000 \\
\hline
\end{tabular}

Taking into account the fact that, in all cases, the regression coefficients of the CD variable with the dependent variables are positive and estimated with $p>|t|=0.000<0.05$, the existence of a positive and significant impact between them results. Thus, a one-unit growth of the $\mathrm{CD}$ variable generates growth in the effectiveness of customer service management practices (CSMG) of 0.4697 units; in pre-transaction effectiveness (PRTP) of 0.4858 units; in transaction effectiveness (TP) of 0.3698 units; in post-transaction effectiveness (PSTP) of 0.4820 units; in customer service effectiveness (CSE) of 0.4518 units. In comparison, we can state that the variation of the $C D$ variable best explains the variation in the effectiveness of the management practices represented by the variable CSMG $(47.02 \%)$.

If we take into account the results of regression analysis, we can highlight the fact that capacity development, as a trait of organizational culture, is a good predictor for customer service effectiveness and for its components.

4.3.2. The Impact of the Independent Variable CV on the Dependent Variables CSMG, PRTP, TP, PSTP, CSE

Starting from the results of the regression analysis (Table 7), we find that, statistically, the independent variable $\mathrm{CV}$ has a significant and positive impact on the dependent variables CSMG, PRTP, TP, PSTP, and CSE.

Table 7. The impact of the independent variable CV on the dependent variables CSMG, PRTP, TP, PSTP, CSE.

\begin{tabular}{ccccccc}
\hline Dependent Variable & N & Prob $>$ F & R-Squared & Coef. & $t$ & $p>|t|$ \\
\hline CSMG & 186 & 0.0000 & 0.7181 & 0.7820693 & 22.23 & 0.000 \\
PRTP & 186 & 0.0000 & 0.6368 & 0.892139 & 14.82 & 0.000 \\
TP & 186 & 0.0000 & 0.4881 & 0.7199097 & 14.90 & 0.000 \\
PSTP & 186 & 0.0000 & 0.6636 & 0.8825777 & 14.08 & 0.000 \\
CSE & 186 & 0.0000 & 0.7186 & 0.819174 & 21.80 & 0.000 \\
\hline
\end{tabular}


Thus, the variation of the $\mathrm{CV}$ variable explains, to a rate of $71.81 \%$, the variation of the variable CSMG; the variation of the variable PRTP $(63.68 \%)$; the variation of the variable TP $(48.81 \%)$; the variation of the variable PSTP $(66.36 \%)$; the variation of the variable CSE (71.86\%). Taking into account the fact that, in all cases, the regression coefficients of the $\mathrm{CV}$ variable with its five dependent variables are positive and estimated at $p>|t|=0.000$, this proves the existence of a positive and significant impact between the $\mathrm{CV}$ variable and the five dependent variables.

The results of regression analysis highlight the fact that the basic values, as a trait of organizational culture, are a good predictor for customer service effectiveness and for its components.

4.3.3. The Impact of the Independent Variable CF on the Dependent Variables CSMG, PRTP, TP, PSTP, CSE

Starting from the results of the regression analysis (Table 8), we find that the independent variable $\mathrm{CF}$ has a significant and positive impact on the studied dependent variables. Thus, the variation of the CF variable explains, to a rate of $66.61 \%$, the variation of the variable CSMG; the variation of the variable PRTP $(63.80 \%)$; the variation of the variable TP $(52.28 \%)$; the variation of the variable PSTP $(56.25 \%)$; the variation of the variable CSE $(68.70 \%)$. We can state, in this case, that the CF variable has a moderate, strong, and positive influence over the five dependent variables.

Table 8. The impact of the independent variable CF on the dependent variables CSMG, PRTP, TP, PSTP, CSE.

\begin{tabular}{ccccccc}
\hline Dependent Variable & N & Prob $>$ F & R-Squared & Coef. & $t$ & $p>|t|$ \\
\hline CSMG & 186 & 0.0000 & 0.66610 & 0.6367565 & 14.69 & 0.000 \\
PRTP & 186 & 0.0000 & 0.63800 & 0.7549161 & 13.22 & 0.000 \\
TP & 186 & 0.0000 & 0.52280 & 0.6298639 & 12.92 & 0.000 \\
PSTP & 186 & 0.0000 & 0.56250 & 0.6869208 & 10.43 & 0.000 \\
CSE & 186 & 0.0000 & 0.68700 & 0.6771143 & 15.48 & 0.000 \\
\hline
\end{tabular}

The regression coefficients of the $\mathrm{CF}$ variable with its five dependent variables are positive and estimated at $p>|t|=0.000$, indicating the existence of a positive and significant impact between the CF variable and all studied dependent variables.

Customer focus facilitates the collection and storage of significant information for the company in a comprehensive database, which allows them to customize the offer on the market and customer service.

The results of regression analysis highlight the fact that customer focus, as a trait of organizational culture, is a good predictor for customer service effectiveness and for its components.

4.3.4. The Impact of the Independent Variable GO on the Dependent Variables CSMG, PRTP, TP, PSTP, CSE

Starting from the results of the regression analysis (Table 9), we can highlight the fact that, statistically, the independent variable GO has a significant and positive impact on the dependent variables.

Table 9. The impact of the independent variable GO on the dependent variables CSMG, PRTP, TP, PSTP, CSE.

\begin{tabular}{ccccccc}
\hline Dependent Variable & N & Prob $>$ F & R-Squared & Coef. & $\boldsymbol{t}$ & $\boldsymbol{p}>|\boldsymbol{t}|$ \\
\hline CSMG & 186 & 0.0000 & 0.5899 & 0.6701519 & 7.73 & 0.000 \\
PRTP & 186 & 0.0000 & 0.5258 & 0.4973777 & 8.49 & 0.000 \\
TP & 186 & 0.0001 & 0.3198 & 0.3804817 & 5.23 & 0.000 \\
PSTP & 186 & 0.0005 & 0.2993 & 0.4684347 & 4.21 & 0.000 \\
CSE & 186 & 0.0000 & 0.6408 & 0.6434689 & 8.06 & 0.000 \\
\hline
\end{tabular}


Thus, the variation of the GO variable explains, to a rate of $58.99 \%$, the variation of the variable CSMG; the variation of the variable PRTP (52.58\%); the variation of the variable TP (31.98\%); the variation of the variable PSTP (29.93\%) and the variation of the variable CSE (64.08\%). We can thus note that the variation of the GO variable best explains the variation of the variables CSE, CSMG, and PRTP. Taking into account the fact that, in all cases, the regression coefficients of the GO variable with its five studied dependent variables are positive and estimated at $p>|t|=0.000$, we can determine the existence of a positive and significant impact between the variable GO and the dependent variables indicating the customer service level.

In conclusion, we can demonstrate that goals and objectives as traits of organizational culture constitute a good predictor for customer service effectiveness and for its components.

The results of the regression analysis (Tables 6-9) highlight the fact that all four traits of organizational culture, represented by the variables $\mathrm{CD}, \mathrm{CV}, \mathrm{CF}$, and $\mathrm{GO}$, are significant predictors of customer service effectiveness improvement, as well as of the improvement of its components, endorsed by responsible corporate governance practices that ensure the promotion of an ethical and sustainable business model.

In conclusion, we can find that the variation of the $\mathrm{CV}$ variable best explains the variation of the variables CSE (71.86\%), CSMG (71.81\%), PSTP (66.36\%), PRTP (63.68\%), TP (48.81\%), with regression coefficients between 0.7199 and 0.8921 . The variation of the CF variable explains the variation of the variables CSE (68.70\%), CSMG (66.61\%), PRTP (63.80\%), PSTP (56.25\%), TP (52.28\%), with regression coefficients between 0.6298 and 0.7549 . The lowest influences are registered by the variation of the GO variable compared to the variation of the variables PSTP $(29.93 \%)$ and TP $(31.98 \%)$, as well as the variation of the CD variable compared to the variation of the variables PRTP $(34.29 \%)$ and TP $(38.47 \%)$.

\subsection{The Link between Organizational Culture, Customer Service Effectiveness, and Sustainability}

Based on the results obtained from the processing and analysis of questionnaire data and of information acquired by direct observation of the four features belonging to the organizational culture, we can see that the analyzed company has an organizational culture that facilitates the integration of sustainability principles in the organization's strategy and practices. In this sense, the company's leadership is firmly committed to:

- Developing employees' capacity: employees are seen as an important source of competitive advantage; innovative practices in the field of human capital management facilitate the involvement of employees in social issues; there are adequate training programs to monitor not only economic performance but also social and environmental performance; promoting teamwork and collaboration; effective operational practices; improving the general and specific skills of employees; improving productivity, involvement and employee satisfaction; attracting and retaining IT talents; creating a work environment that stimulates both economic performance and social and environmental performance; ensuring occupational health and safety.

- Sharing common core values is an important means of support in ensuring the sustainability of a company, by improving financial, social, and environmental performance. As shown in Section 4.1, out of the top 10 values appreciated by respondents, "customer first" and "innovation" are essential for achieving economic performance, "teamwork", "communication" and "care of people" are essential for ensuring social performance, to which is added the "right to privacy". The concept of a work-life balance becomes a key component of social sustainability, both at the level of individual organizations and at a more general level represented by global institutions [41]. At the same time, accountability demonstrates concern for the acquisition of appropriate skills, promotes equal opportunities and socio-cultural diversity. The fundamental values of the company the employees believe in guide them in making decisions and strengthen a corporate culture oriented towards sustainability, which promotes strengthening the feeling of belonging to the company. At the same time, it guides the company's social responsibility policy concerning the community. 
- Customer orientation ensures the building of strong relationships with customers for a better understanding of their requirements and expectations, as well as for the development of a culture in which each employee considers the customer as a priority. Employees have the appropriate professional knowledge and skills to provide quality customer service as a source of competitive advantage that aligns their functional capacity with the company's strategy, thus facilitating increased organizational effectiveness. The evaluation of customer relations takes into account the promotion of appropriate and fair social practices, as well as the impact of the company's activities on the natural environment and business ethics.

- The development of a strong culture based on ambitious and realistic goals and objectives for the economic, social and environmental dimension, with a strong customer orientation as well as a system of common core values, shared by company members, facilitates meeting current and strategic objectives at high-performance standards, financially, socially and environmentally. Ensuring the appropriate flow of information to assess the impact of the company's policies and strategies on sustainability.

To be able to approach customer service from the perspective of sustainability, we must start from the requirements underlying the company's assessment as a supplier by its customers in the business-to-business relationship in order to perform customer service according to their expectations and requirements.

To develop long-term competitive relationships based on trust and collaboration with customers, the company must demonstrate the application of appropriate corporate governance practices by adopting strategies and practices at the operational level to meet current company objectives and interested parties' requirements, simultaneously interested in protecting, maintaining, and improving the human and natural resources that will be needed in the future. To this end, the analyzed company aims to integrate the principles of sustainability in its strategies and practices towards "forming the future society along with its customers" by offering solutions for the sustainable development of its customers and society, while contributing to solving social problems through its corporate activities, considering the cultivation of IT talent, respecting diversity, and improving corporate sustainability.

In the field of the environment, the company integrates into its strategy and practices (including those related to customer service), the following specific objectives: reducing greenhouse gas emissions; promoting energy efficiency in data centers and office buildings; responsible use of natural resources, reduction in water, gas, and consumables consumption, which are monitored monthly to find the best solutions for their optimization. This is facilitated by the establishment of an environmental council within the board of directors as an effective corporate governance structure that monitors and maintains permanent contact with both the company's management and employees through a dedicated internal application.

Corporate governance as a means of support for sustainability aims to ensure the security and confidentiality of information by protecting information assets not only of the customers but also of the company against cyber-attacks and other risks.

In assuming responsibility of customers and other stakeholders, important support is provided by implementing and operationalizing the requirements of voluntary standards on quality management (ISO 9001: 2015), environmental management (ISO 14001: 2015), occupational health and safety management (OHSAS 18001: 2007), information security management (ISO 27001: 2013) and social responsibility management (ISO 26000: 2010), which operates in the form of an integrated management system. Both the DSJ index criteria for the economic and social dimension, as well as the FTSE4Good and RobecoSAM Sustainability Award Gold Class criteria for the social and environmental dimension are added to these. To assess the level of sustainability of the analyzed company, we will further present some relevant successful actions, starting from the business model presented in the study, in addition to the achievements of leadership in integrating sustainability principles based on common values shared with employees in corporate culture and sustainability objectives in the organization's strategy and practices, which are found in all of its processes and activities. 
As a member of the multinational group, the company implemented the concept of corporate social responsibility (CSR) in a broad sense to ensure sustainable growth, which refers to the integration of sustainability principles with a support system of common fundamental values in the organizational culture, in its strategy and operations, as well as in the decision-making process-a point of view that is sustained in the specialized literature $[1,4,74,75]$.

Within the multinational group, a CSR committee was formed and a CSR Charter of the Group was elaborated. In addition, the CSR manual at the company level was elaborated. The following are the most relevant sustainability aspects in the three areas, namely, business, social, and environmental, along with corporate governance:

- In the business field (innovation): has implemented the criteria of the DJS index regarding the implementation of corporate governance's principles, risk management, and ethics, through the code of conduct. Likewise, offering social infrastructure and appropriate solutions based on advanced technologies to provide customers with products/services that leverage digital technologies to address societal issues and ensure a high level of service provided to customers.

- In the social field: has implemented the criteria of the DJS and FTSE4Good indexes (related to employees) on human capital development, attracting and retaining talent, innovative human capital practices, employee development, occupational health and safety, equal opportunity policies, security and employee development in the IT field and the promotion of socio-cultural diversity. In addition, in the relationship with the community, the behavior of the "good corporate citizen" and philanthropy.

- In the field of the environment: as an information service provider, there is an environmental policy that aims to deliver environmentally responsible systems and services to actively participate in activities aimed at reducing the impact on the environment. The criteria of the FTSE4Good and RobecoSAM Sustainability Award Gold Class indexes are implemented regarding the sustainable development of the environment and reduction in greenhouse gas emissions. To achieve this goal the company promotes energy efficiency.

- In the field of governance: ensuring the security of information concerning both the company and the clients against cyber-attacks and other risks; properly ensuring the confidentiality of information and protecting the rights of human beings, company customers and other stakeholders; ensuring compliance by informing and training employees; promoting the company's cooperation with business partners in environmental protection; promoting CSR in the supply chain.

The results in meeting the objectives of corporate sustainability can be highlighted through an integrative culture for sustainability and responsible practices. Said practices are to ensure economic, social and environmental performance with regard to the effective implementation and operationalization of customer service. We can exemplify this through several relevant successful actions:

- In the economic field: the company has very good results if we refer first to the clients and their maintenance, and second to the market share and the profitability.

- In the social field: digitization (largely) of contacts with customers; implementing the uses of the digital signature in the relationship with clients; combating discrimination; ensuring health and safety of employment, etc. Therewith we mention that in the relationship with the local community, the analyzed company is acknowledged on two levels of social responsibility: the support of institutions and socio-cultural events, respectively, and the support of critical social situations and ensuring sustainable jobs for young graduates facing problems entering the labor market (in mature markets).

- In the field of the environment: improving environmental management by equipping the company's office buildings with air conditioning with low energy consumption; the purchase of electric cars in the car park; as a permanent objective, the company contributes to achieving the group's objective of improving long-term energy efficiency so that by 2030 , at least $30 \%$ of 
the consumed energy is from renewable resources, in addition to the goal of producing zero waste. Besides reducing waste, the company promotes the development of a system responsible for the environment through active involvement in ecological procurement, together with the implementation of effective policies for saving resources and energy, besides reducing waste.

- In the relationship with customers: collaborative platforms have been implemented between the company and customers, which ensure the significant reduction in delegations generated by direct contacts with customers (meetings, workshops), with a significant and positive impact on the environment and care for people (employees). The company promotes progressive initiatives in greening customers and society through its products and services; for example, construction and implementation of fire protection systems in secluded forests that are difficult to access; another project, regarding the implementation and monitoring of soil and air characteristics to support an eco-agriculture; projects for optimizing transport routes of car fleets, etc. The company implemented programs aimed at formalizing and increasing the quality of support services offered to customers by defining their specific processes, commercial offers, and developing effective practices for the operationalization of customer service.

- Corporate governance: the employees share a system of common values, thus supporting the company's social responsibility policy. The company has ethical and transparent corporate governance practices, thus ensuring economic, social, and environmental performance, in addition to compliance with environmental and social standards, as well as harmonization of relations with the main stakeholders.

The taken actions and the obtained results demonstrate that the company can maintain its performance for a long time, not only in the economic field (in our case improving the customer service effectiveness) but also in the social and environmental fields. All these actions ensure a high level of sustainability.

As a conclusion, we can say that the business model adopted in this study, from the perspective of sustainability, reveals the impact of organizational culture, which integrates the principles of sustainability with customer service effectiveness, which, in turn, integrates with the organization's strategy, practices and processes, demonstrating that the analyzed company successfully promotes an ethical and sustainable business model, which through the results obtained can be considered a benchmark in the field in which it operates.

\section{Conclusions}

The conducted research, in terms of theoretical contribution, based on relevant literature, provides a contextual theoretical framework and a methodology suitable for conducting an empirical study at a multinational company in the IT field. At the same time, the results of this study show that organizational culture, represented by the four features capacity building, core values, customer orientation, and goals and objectives, acts as an important predictor for improving customer service and its components, respectively, effectiveness of management practices, pre-transaction, transaction, and post-transaction.

The results of the analysis model confirmed that the organizational culture, through the four features, largely explains the variation of customer service with all its components and has a significant and positive impact on customer service with all its components (Tables 6-9). This means that the four hypotheses, $\mathrm{H} 1, \mathrm{H} 2, \mathrm{H} 3$, and $\mathrm{H} 4$, are fully verified and explain that the analyzed company promotes a strong culture, through appropriate and effective management practices on capacity development, common core values, strong customer orientation, as well as goals and objectives, which ensure the company's ability to effectively implement, operationalize and monitor customer service to ensure competitive advantage.

The empirical study highlighted the role of implementing strategies, policies, and practices on strategic customer service. However, we must specify that there is no single approach in the specialized literature of strategic customer service management. Thus, some authors mainly considered 
the different conceptual and methodological aspects, while others were guided by the principles of measuring customer service practices in the three phases considered to provide guidance that can be practiced, namely, pre-transaction, transaction and post-transaction. More specifically, practice-oriented research examines individual practices such as operationalizing and monitoring customer service, identifying those practices that contribute to increasing organizational effectiveness with the ultimate goal of developing a guide to good practice in the field $[7,8,47,57,63,67,77]$. Other research, considered principle-oriented, focuses on principles guiding the development of practices, such as the company focusing on the customer (customer-centric company) [7,51,63,66,71,73,77-79].

Based on these findings, we can show that the distinction between practice-oriented and principle-oriented research that underlies the effectiveness of customer service is important only for the way researchers conceptualize its management in a strategic approach. Our study has a multidimensional approach to customer service based on both guidelines, which can only be effective if they are approached together, especially in empirical studies. At the same time, it provides suitable support to the decision-making system in the process of developing and monitoring standards, together with measures to improve the effectiveness of customer service, as well as awareness of its importance by the members of the company.

Given that effective customer service management practices add value and can be a source of tangible benefits that contributes to an effective and efficient use of the organization's resources, the empirical study, on the one hand, aims to highlight management practices as a source of competitive advantage at all levels of the organization and, on the other hand, refers to the ability of the organization to manage customer service.

In terms of novelty and practical contribution, both the results and conclusions of our study, on the one hand, legitimize and support the opinions of recognized researchers and practitioners in the field and, on the other hand, extend the conclusions of studies presented in the literature with the analysis of the relationship between the four features of organizational culture and customer service effectiveness in a multinational company from the ITC industry.

Our research supports the view that an important source of competitive advantage is not only the ability to manage this service, which targets the company's skills and dynamics of customer relationships, but also the range of methods, techniques and tools applied in customer relationship management, among which customer experience management plays a key role. As a result, the customer service managerial perspective emphasizes not only the processes that underpin customer relationships, but also the importance of employee skills that can be developed in response to positive customer experiences, together with the dynamics of the internal and external environment.

The respondents to the study appreciate the ways and standards at which the activities and processes that define the customer service of the company are performed in all its phases (pre-transaction, transaction, post-transaction), representing the company's ability to constantly provide a competitive service. This means that for the success of the relationship with customers and to ensure the effectiveness of customer service, a permanent balance between the company's processes, employee skills, as well as meeting customer expectations and requirements must be provided.

Good practices that have been taken into account in the design, operationalization and monitoring of customer service can create value for the analyzed company. Equally, they can represent a standard of performance in the internal benchmarking process, or a relevant evaluation performed by external auditors.

The entire approach and the results of the study demonstrate that the analyzed company promotes a business model, which expresses the integration of sustainability principles in the organization's culture and its impact on customer service effectiveness, thus integrating specific sustainability objectives into the organization's strategy and practices. All these ensures the successful promotion of an ethical and sustainable business model, which could be a benchmark in the field in which it operates.

The use of the analysis model suggests that good practices can help managers identify and make changes when required. 
The good practices we considered in the empirical study not only offer generic solutions but, by appropriate measures, can be effectively applied within the analyzed company.

Starting from the results of the empirical study, from the analyses performed by the company on the customer experience and from the effective contact of the authors with the customers, we consider that ensuring service efficacy to the customer, as a source of competitive advantage, requires a firm and informed commitment of the company regarding the following aspects:

- Customer service must be considered by the company's members as an important priority, as a source for ensuring market competitiveness, given the great diversity and complexity of the products in its portfolio, to which is added the ever-increasing customer requirements in an increasingly competitive market, which increases efforts to maintain the competitive advantage;

- Customer policy must be accompanied by a "mission statement", which must include not only performance standards but also the obligations and commitments of the departments involved in ensuring a competitive level of customer service;

- The company's managers, through adequate analyses, must highlight the links between the level of performance of the service provided to the customer and the financial indicators (associated costs and revenues);

- Identifying and implementing good human capital management practices for employees who are involved in customer service to improve their contribution to achieving a highly competitive level;

- Employees should receive appropriate training and assistance through appropriate and effective training programs to help them identify the principles and practices that underpin customer service excellence to effectively design and operationalize their improvement programs;

- Adequate and effective communication to company employees, specific objectives and customer service policy to understand the needs of customers, the market and the competitive environment;

- The development of a culture of excellence in customer service must be an essential goal;

- The strategic approach of customer service as a permanent business process and the alignment of the strategies and of the policies with the improvement of customer service effectiveness and of customer experience in order to involve them in the design and improvement process;

- The multidimensional approach of the customer experience, which contributes to the formation of a holistic vision of all customer interactions, even if it involves costs and can create difficulties in administration and control;

- Ensuring a flexible structure appropriate to customer service, allowing it to achieve its specific objectives, and identifying the main areas for improvement;

- An adequate organizational infrastructure to ensure the effectiveness and efficiency of customer service, by integrating the responsibilities of all those involved in customer service and functional alignment to the highest possible standards of the service provided;

- Building strategic alliances with customers increasingly focused on understanding their needs and expectations by developing active partnerships with customers for their effective involvement in the production and provision of products and services to make the best use of market opportunities.

Given the specificity of the field, the study focused on a single company that has over 2000 employees in Romania, is part of a multinational group in the IT industry, and operates not only in the Romanian market but also in the European and Asian markets. The limitations of the research from a methodological and conceptual point of view refer to the choice of a case study of a single company that does not facilitate the identification of all significant connections between the variables that are the object of analysis and that cannot be generalized. Furthermore, the transversal type of the research does not facilitate the study of evolution in time of the changes in the used variable change, nor the examination of different processes relevant for the implementation and operationalization of the service to the client. The case study allowed us to collect data on the actual activity carried out within the company and to observe in detail the issues addressed. The analysis of the data and information provided by the case study allowed us to identify the most relevant aspects regarding 
the design, implementation, and operationalization of customer service as well as the influence of the organizational culture on it. At the same time, it allowed for improved understanding of the studied field and additional refinement of the theory in the researched field, as well as the identification of some ways of integrating the principles of sustainability in the company's culture. We must emphasize that the case study is relevant not only in terms of its systematic approach of the subject but also its orientation towards the improvement of knowledge in the field. This was also facilitated by the expertise and experience of the researchers participating through direct observation not only in the collection of data and information but also in the qualitative analysis of documents.

Author Contributions: Conceptualization, D.M., L.I. and R.L.N.; data curation, D.M., L.I. and R.L.N.; formal analysis, D.M., L.I. and R.L.N.; funding acquisition, D.M.; investigation, D.M., L.I. and R.L.N.; methodology, D.M., L.I. and R.L.N.; project administration, D.M. and L.I.; resources, D.M. and L.I.; software, D.M. and L.I.; supervision, D.M., L.I. and R.L.N.; validation, D.M., L.I. and R.L.N.; visualization, D.M. and L.I.; writing一original draft, D.M., L.I. and R.L.N.; writing-review and editing, D.M., L.I. and R.L.N. All authors have read and agreed to the published version of the manuscript.

Funding: This research received no external funding.

Conflicts of Interest: The authors declare no conflict of interest.

\section{References}

1. Heskett, J.L.; Sasser, W.E. The Service Profit Chain; Springer Science and Business Media LLC: Berlin, Germany, 2010; pp. 19-29.

2. Tao, F. Customer Relationship management based on Increasing Customer Satisfaction. Int. J. Bus. Soc. Sci. 2014, 5, 256-263.

3. Edgeman, R. Performance Management and Enterprise Excellence through Sustainable Business Models. In Sustainable Business Models; Springer Science and Business Media LLC, Springer Nature: Cham, Switzerland, 2018; pp. 317-359.

4. Heizer, J.; Render, B.; Munson, C. Operations Management: Sustainability and Supply Chain Management, 12th ed.; Pearson Education, Inc.: Essex, UK, 2017.

5. Drosos, D.; Skordoulis, M.; Arabatzis, G.; Tsotsolas, N.; Galatsidas, S. Measuring Industrial Customer Satisfaction: The Case of the Natural Gas Market in Greece. Sustainability 2019, 11, 1905. [CrossRef]

6. Vilkaitè-Vaitonè, N.; Skackauskiene, I. Service Customer Loyalty: An Evaluation Based on Loyalty Factors. Sustainability 2020, 12, 2260. [CrossRef]

7. Christopher, M. Logistics and Supply Chain Management: Creating Value-Adding Networks, 3rd ed.; FT Prentice Hall: London, UK, 2005.

8. Goodman, J.A. Strategic Customer Service: Managing the Customer Experience to Increase Positive Word of Mouth, Build Loyalty, and Maximize Profits; AMACOM: New York, NY, USA, 2009.

9. Blanding, W. Practical Handbook of Customer Service Operations; International Thomson Transport Press: Washington, DC, USA, 1989.

10. Kaplan, R.S.; Norton, D.P. Transforming the Balanced Scorecard from Performance Measurement to Strategic Management: Part II. Account. Horiz. 2001, 15, 147-160. [CrossRef]

11. Schaltegger, S.; Ludeke-Freund, F.; Hansen, E.G. Business Cases for Sustainability and the Role of Business Model Innovation: Developing a Conceptual Framework. SSRN Electron. J. 2011, 6, 95-119. [CrossRef]

12. Jolink, A.; Niesten, E. Sustainable Development and Business Models of Entrepreneurs in the Organic Food Industry. Bus. Strat. Environ. 2013, 24, 386-401. [CrossRef]

13. Stubbs, W. Characterising B Corps as a sustainable business model: An exploratory study of B Corps in Australia. J. Clean. Prod. 2017, 144, 299-312. [CrossRef]

14. Stubbs, W.; Cocklin, C. Conceptualizing a "Sustainability Business Model”. Organ. Environ. 2008, 21, $103-127$. [CrossRef]

15. Magretta, J. Why business models matter. Harv. Bus. Rev. 2002, 80, 86-92.

16. Osterwalder, A.; Pigneur, Y.; Tucci, C.L. Clarifying Business Models: Origins, Present, and Future of the Concept. Commun. Assoc. Inf. Syst. 2005, 16, 1. [CrossRef]

17. Boons, F.; Lüdeke-Freund, F. Business models for sustainable innovation: State-of-the-art and steps towards a research agenda. J. Clean. Prod. 2013, 45, 9-19. [CrossRef] 
18. Evans, S.; Vladimirova, D.; Holgado, M.; Van Fossen, K.; Yang, M.; Silva, E.A.; Barlow, C.Y. Business Model Innovation for Sustainability: Towards a Unified Perspective for Creation of Sustainable Business Models. Bus. Strat. Environ. 2017, 26, 597-608. [CrossRef]

19. Nosratabadi, S.; Mosavi, A.; Shamshirband, S.; Zavadskas, E.K.; Rakotonirainy, A.; Chau, K.-W. Sustainable Business Models: A Review. Sustainability 2019, 11, 1663. [CrossRef]

20. Birkin, F.; Cashman, A.; Koh, S.C.L.; Liu, Z. New sustainable business models in China. Bus. Strat. Environ. 2009, 18, 64-77. [CrossRef]

21. Gulati, R.; Kletter, D. Shrinking Core, Expanding Periphery: The Relational Architecture of High-Performing Organizations. Calif. Manag. Rev. 2005, 47, 77-104. [CrossRef]

22. O'Reilly, C.A.; Caldwell, D.F.; Chatman, J.A.; Doerr, B. The Promise and Problems of Organizational Culture. Group Organ. Manag. 2014, 39, 595-625. [CrossRef]

23. Denison, D.R.; Hooijberg, R.; Lane, N.; Lief, C. Change in Global Organizations: Aligning Culture and Strategy; Jossey Bass: San Francisco, CA, USA, 2012.

24. Tierney, W.G.; Schein, E.H. Organizational Culture and Leadership. Acad. Manag. Rev. 1986, 11, 677. [CrossRef]

25. Fey, C.F.; Denison, D.R. Organizational Culture and Effectiveness: Can American Theory be Applied in Russia? Organ. Sci. 2003, 14, 686-706. [CrossRef]

26. Denison, D.R.; Haaland, S.; Goelzer, P. Corporate Culture and Organizational Effectiveness. Organ. Dyn. 2004, 33, 98-109. [CrossRef]

27. Denison, D.R.; Mishra, A.K. Toward a Theory of Organizational Culture and Effectiveness. Organ. Sci. 1995, 6, 204-223. [CrossRef]

28. Denison, D.R.; Neale, W.S.; Denison, D.R.; Neale, W.S. Denison Organizational Culture Survey. In PsycTESTS Dataset; American Psychological Association (APA): Washington, DC, USA, 1996.

29. Marcoulides, G.A.; Heck, R.H. Organizational Culture and Performance: Proposing and Testing a Model. Organ. Sci. 1993, 4, 209-225. [CrossRef]

30. Denison, D.R. Corporate Culture and Organizational Effectiveness; John Wiley \& Sons: New York, NY, USA, 1990.

31. Denison, D.R.; Janovics, J.; Young, J.; Cho, H.J. Diagnosing Organizational Cultures: Validating a Model and Method; Denison Consulting Group: Carlisle, PA, USA, 2006.

32. Ouchi, W.G. Organizational paradigms: A commentary on Japanese management and theory Z organizations. Organ. Dyn. 1981, 9, 36-43. [CrossRef]

33. Robbins, S.; Coulter, M. Management, 14th ed.; Pearson Education, Inc.: New York, NY, USA, 2018.

34. Kinicki, A.; Williams, B.K. Management: A Practical Introduction, 8th ed.; McGraw Hill Education: New York, NY, USA, 2018.

35. Deal, T.E.; Kennedy, A.A. Corporate Cultures: The Rites and Rituals of Corporate Life; Addison Wesley Publishing Company: Reading, MA, USA, 1982; p. 126.

36. Piwowar-Sulej, K. Pro-Environmental Organizational Culture: Its Essence and a Concept for Its Operationalization. Sustainability 2020, 12, 4197. [CrossRef]

37. Post, J.E.; Altma, B.W. Managing the Environmental Change Process: Barriers and Opportunities. J. Organ. Chang. Manag. 1994, 7, 64-81. [CrossRef]

38. Stead, J.G. Eco-Enterprise Strategy: Standing for Sustainability. J. Bus. Ethics 2000, 24, 313-329. [CrossRef]

39. Welford, R. Attitudes towards environmental management. Bus. Strat. Environ. 1995, 4, 40-41. [CrossRef]

40. Eccles, R.G.; Ioannou, I.; Serafeim, G. The Impact of a Corporate Culture of Sustainability on Corporate Behavior and Performance. SSRN Electron. J. 2011. [CrossRef]

41. Gálvez, A.; Tirado, F.; Martínez, M.J. Work-Life Balance, Organizations and Social Sustainability: Analyzing Female Telework in Spain. Sustainability 2020, 12, 3567. [CrossRef]

42. Allen, R.S.; Helms, M.M. Linking strategic practices and organizational performance to Porter's generic strategies. Bus. Process. Manag. J. 2006, 12, 433-454. [CrossRef]

43. Denison Consulting. Introduction to the Denison Model. Research Note; Denison Consulting: Ann Arbor, MI, USA, 2006.

44. Xuan, T.T.H.; Hao, N.Đ.; Phuc, N.T. Organizational Culture of Enterprises in Thua Thien Hue Province With Denison Model. Hue Univ. J. Sci. Econ. Dev. 2019, 128, 45-54. [CrossRef] 
45. Nazir, N.A.; Lone, M.A. Validation of Denison's Model of Organisational Culture and Effectiveness in the Indian Context. Vision 2008, 12, 49-58. [CrossRef]

46. Murphy, P.R., Jr.; Knemeyer, A.M. Contemporary Logistics, 12th ed.; Pearson Education Limited: New York, NY, USA, 2018.

47. Oloruntoba, R.; Gray, R. Customer service in emergency relief chains. Int. J. Phys. Distrib. Logist. Manag. 2009, 39, 486-505. [CrossRef]

48. Gronroos, C. Service Management: Customer Management in Service Competition; John Wiley \& Sons Limited: Chichester, UK, 2007.

49. Sheth, J.N.; Sisodia, R.S.; Sharma, A. The Antecedents and Consequences of Customer-Centric Marketing. J. Acad. Mark. Sci. 2000, 28, 55-66. [CrossRef]

50. Payne, A.; Frow, P. A Strategic Framework for Customer Relationship Management. J. Mark. 2005, 69, 167-176. [CrossRef]

51. Ballou, R.H. Business Logistics-Supply Chain Management Planning, Organizing, and Controlling the Supply Chain, 5th ed.; Pearson Prentice Hall International Inc.: Upper Saddle River, NJ, USA, 2004.

52. Hollingworth, M. Building 360 organizational sustainability. Ivey Bus. J. 2009. Available online: https: //iveybusinessjournal.com/publication/building-360-organizational-sustainability (accessed on 11 June 2020).

53. Galpin, T.; Whitttington, J.L.; Bell, G. Is your sustainability strategy sustainable? Creating a culture of sustainability. Corp. Gov. Int. J. Bus. Soc. 2015, 15, 1-17. [CrossRef]

54. Rushton, A.; Croucher, P.; Baker, P. The Handbook of Logistics and Distribution Management; Kogan Page: London, UK, 2014.

55. Rushton, A.; Croucher, P.; Baker, P. The Handbook of Logistics E Distribution Management; Kogan Page; The Chartered Institute of Logistics and Transport: London, UK, 2006.

56. Bălan, C. Logistică; Editura Uranus: Bucharest, Romania, 2006.

57. Lambert, D.M.; Stock, J.R. Strategic Logistics Management; Richard D. Irwin, Inc.: Boston, MA, USA, 1993.

58. Jeffery, M.M.; Butler, J.R.; Malone, C.L. Determining cost effective customer level service. Supply Chain Manag. 2008, 13, 225-232. [CrossRef]

59. Snow, D.; Yanovitch, T. Unleashing Excellence. The Excellence, The Complete Guide to Ultimate Customer Service, 2nd ed.; John Wiley \& Sons Inc.: Hoboken, NJ, USA, 2010.

60. Ilieş, L. Managementul Firmei; Dacia: Cluj-Napoca, Romania, 2001.

61. De Waal, A.; Kourtit, K. Performance measurement and management in practice. Advantages, disadvantages and reasons for use. Int. J. Prod. Perform. Manag. 2013, 62, 446-473. [CrossRef]

62. La Londe, J.B.; Zinszer, H.P. Customer Service: Meaning and Measurement. Chic. Natl. Counc. Phys. Distrib. Manag. 1976, 1, 181-192.

63. Stock, J.R.; Lambert, D.M. Strategic Logistics Management; McGraw Hill: New York, NY, USA, 2001.

64. Ilieș, L. Management Logistic; Editura Dacia: Cluj-Napoca, Romania, 2003.

65. Ilieș, L.; Crișan, E.; Salanță, I. Managementul Logisticii; Risoprint: Cluj-Napoca, Romania, 2011.

66. Crişan, E.; Ilieş, L.; Salanţă, I. Management Best Practices Used in Romanian Logistics Customer Service Planning. Amfiteatru Econ. J. 2010, 12, 215-227.

67. Christopher, M. Logistics and Supply Chain Management; Pitman Publishing: London, UK, 1992.

68. Grant, D. Fundamentals of Logistics Management; McGraw-Hill Education: New York, NY, USA, 2006.

69. Al-Tit, A.A. Factors affecting the organizational performance of manufacturing firms. Int. J. Eng. Bus. Manag. 2017, 9, 9. [CrossRef]

70. Ittner, C.D.; Larcker, D.F.; Rajan, M.V. The choice of performance measures in annual bonus contracts. Acc. Rev. 1997, 72, 231-255.

71. Kamin, M. Customer Service Training; Informa UK Limited: Oxford, UK, 2006.

72. Bowersox, D.J.; Closs, D.J.; Cooper, M.B. Supply Chain Logistics Management; Mcgraw-Hill: Boston, MA, USA, 2002.

73. Ukens, L.L. 101 Ways to Improve Customer Service; John Wiley \& Sons, Inc.: New York, NY, USA, 2007.

74. Linnenluecke, M.K.; Griffiths, A. Corporate sustainability and organizational culture. J. World Bus. 2010, 45, 357-366. [CrossRef]

75. Berger, I.E.; Cunningham, P.H.; Drumwright, M.E. Mainstreaming Corporate Social Responsibility: Developing Markets for Virtue. Calif. Manag. Rev. 2007, 49, 132-157. [CrossRef] 
76. Conrad, C.A.; Brown, G.; Harmon, H.A. Customer satisfaction and corporate culture: A profile deviation analysis of a relationship marketing outcome. Psychol. Mark. 1997, 14, 663-674. [CrossRef]

77. Welsh, K. Happy About Customer Service? Creating a Culture of Customer Service Excellence; Happy About: Silicon Valley, CA, USA, 2008.

78. Fawcet, P.; Mcleish, R.E.; Ogden, L.D. Logistics Management; Pitman Publishing: London, UK, 1992.

79. Gilmour, P. Logistics Management; Longman: Melbourne, Australia, 1993.

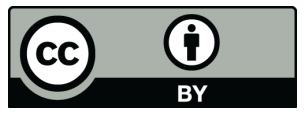

(C) 2020 by the authors. Licensee MDPI, Basel, Switzerland. This article is an open access article distributed under the terms and conditions of the Creative Commons Attribution (CC BY) license (http://creativecommons.org/licenses/by/4.0/). 